\title{
Desarrollo rural y movilización social en la zona rural de la Subcuenca del Río Pance (Cali, Colombia) ${ }^{* *}$
}

\author{
Rural development and social mobilization in rural areas \\ of the Subwatershed of the Pance River (Cali, Colombia) \\ Desenvolvimento rural e mobilização social na zona rural \\ da Sub-bacia do Rio Pance (Cali, Colômbia)
}

\footnotetext{
* Magíster en Sociedades Rurales de la Universidad de Caldas (Manizales). Antropóloga de la Universidad Externado de Colombia. Miembro del Working Group on Indigenous and Tribal Issues del Consejo de Cooperación Sur-Sur para el Desarrollo Sostenible (CCSS). Profesora e investigadora sobre estudios regionales, urbanos y rurales con énfasis en medio ambiente, territorio, memoria social, salud pública, seguridad y narcotráfico.

** Este artículo es producto del análisis de los resultados del proyecto de investigación «Caudal de gentes, caminos de río. Estudio etnográfico sobre territorialidades de Pance», financiado por Colciencias (Departamento Administrativo de Ciencia, Tecnología e Innovación de Colombia) y la Universidad Icesi dentro del programa Jóvenes investigadores del 2012-2013. Artículo de investigación recibido el 30-08-2016 y aceptado 27-02-2017.
} 


\section{Cómo citar}

PÉREZ, N. (2017). Desarrollo rural y movilización social en la zona rural de la Subcuenca del Río Pance (Cali, Colombia). Revista CS, 21, pp. 69-96. Cali, Colombia: Facultad de Derecho y Ciencias Sociales, Universidad Icesi.

DOI: http://dx.doi.org/10.18046/recs.i21.2273 


\section{Resumen}

Abstract

Resumo

En el corregimiento de Pance (Cali, Valle del Cauca, Colombia), se han generado claras preocupaciones sobre la planeación territorial local, no solo como corregimiento sino como micro cuenca. El objetivo del presente artículo es analizar la correlación entre el modelo del actual Plan de Ordenamiento Territorial de la ciudad de Cali y las transformaciones organizativas comunitarias que emergen entre la población del corregimiento de Pance. Para esto se describe el contexto socio económico y político de la sub-cuenca, caracterizando sus relaciones socioeconómicas y culturales. Posteriormente se realiza una aproximación teórico-conceptual a las principales teorías del desarrollo y los principales enfoques del desarrollo rural, con el propósito de identificar el modelo de desarrollo que corresponde al ordenamiento de Cali. Por último, se aporta una reflexión sobre la relación entre las políticas de ordenamiento local-municipal y las nuevas formas de organización y movilización comunitaria.

\section{PALABRAS CLAVE:}

Territorio rural | planeación territorial | movilización social y desarrollo

In the subwatershed of Pance river (Cali, Valle del Cauca, Colombia), the community is concerned with local territorial planning. The objective of this article is to analyze the correlation between the territorial ordering model of Cali and the community organizational transformations which are emerging in Pance. It describes the socioeconomic and political context of the subwatershed, in a social and cultural characterization of its relations. Later, a theorical and conceptual approach is made to the main theories of development, and the main approaches to rural development is made. Its goal is to identifying the development model of Cali's ordering model. Finally, this article contributes with an in-depth of the relationship between the policies of local-municipal order and the new forms of organization and community mobilization.

\section{KEYWORDS:}

Rural territory | territorial planning | social organization and development 
No corregimento de Pance (Cali, Valle del Cauca, Colômbia), tem gerado claras preocupações sobre o planejamento territorial local, não somente como corregimento senão como microbacia. O objetivo do presente artigo é analisar a correlação entre o modelo do atual Plano de Gestão Territorial da cidade de Cali e as transformações organizacionais comunitárias que emergem entre a população do corregimento de Pance. Para isso, descreve-se o contexto sócio-econômico e político da sub-bacia, caracterizando suas relações sócio-econômicas e culturais. Posteriormente, realiza-se uma aproximação teórico-conceitual às principais teorias do desenvolvimento e as principais abordagens do desenvolvimento rural, com o propósito de identificar o modelo de desenvolvimento que corresponde ao ordenamento de Cali. Por último, fornece-se uma reflexão sobre a relação entre as políticas de gestão local-municipal e as novas formas de organização e mobilização comunitária.

\section{PALAVRAS CHAVES:}

Território rural | planejamento territorial | mobilização social e desenvolvimento 


\section{Introducción}

La creciente presión ambiental y demográfica que se ha ejercido sobre la subcuenca del río Pance, como resultado de la expansión urbana de Cali y el acelerado desarrollo sin planeación del sector del turismo dentro de la economía de la micro-cuenca, han desencadenado en la población habitante incipientes preocupaciones, movilizaciones, procesos y proyectos de reconocimiento de su propio contexto, con el objetivo de cuestionarse sobre las posibles alternativas de supervivencia en la zona. Paralelamente han emergido investigaciones que articulan la academia con la comunidad, como el proyecto «Caudal de gentes, caminos de río - Estudio etnográfico sobre territorialidades de Pance», financiado por Colciencias y la Universidad Icesi dentro del programa jóvenes investigadores del 2012. Su objetivo fue analizar los procesos de construcción de territorialidad del corregimiento de Pance de la ciudad de Cali (Valle del Cauca), a través de un análisis de las relaciones políticas, económicas y socioculturales de los diversos actores, además de las incongruencias entre políticas públicas y proyectos sociales y ambientales dirigidos a la población local.

El presente análisis se realiza sobre la correlación entre las actuales estructuras organizativas del corregimiento de Pance y los mecanismos e instrumentos de ordenamiento que definen los lineamientos de manejo, control y administración de zonas tanto urbanas como rurales, como es el caso del Plan de Ordenamiento Territorial (POT). El cual, al ser comprendido como un proceso de participación e incidencia política, puede comenzar a ser aprehendido por la comunidad como una herramienta de organización política. Por tanto, será necesario realizar una descripción del contexto socio económico y político de la subcuenca y una aproximación teórico-conceptual a las principales teorías del desarrollo y los principales enfoques del desarrollo rural.

En términos metodológicos, para el estudio etnográfico se recurrió al uso de técnicas de investigación cualitativa como las historias de vida y la cartografía social, dado el interés por el análisis sobre territorialidad como espacio de representación del territorio. La cartografía social aplicada, por un lado, para la lectura de la relación social entre individuo-territorio, naturaleza-cultura; y por otro sobre la socialización de las concepciones espacio-temporales tanto individuales como colectivas, donde el auto-reconocimiento de los saberes sobre el territorio es también una estrategia de transformación social.

El documento inicialmente ofrece una descripción de la ubicación de la zona y una caracterización política, económica, social y ambiental. Posteriormente se realiza una aproximación teórico-conceptual a las principales teorías del desarrollo, y los principales enfoques del desarrollo rural, con el propósito identificar el modelo de desarrollo al cual corresponde el modelo de ordenamiento de Cali. Por último, se aporta una reflexión sobre la relación entre las políticas de ordenamiento local-municipal y las nuevas formas de organización y movilización comunitaria. 


\section{Corregimiento de Pance, Valle del Cauca}

Con cuatro grandes cuencas hidrográficas, Colombia es uno de los diez países con mayor generación de agua en el mundo. En el departamento del Valle del Cauca, el municipio de Santiago de Cali cuenta con uno de los patrimonios naturales más importantes de Colombia: el Parque Natural Nacional Farallones de Cali, que alberga una importante área de reserva forestal, $\mathrm{y}$ donde nacen numerosas fuentes de agua que desembocan tanto al Océano Pacífico (Verde, Anchicayá, San Agustín, Cajambre, Yurumanguí y Naya) como al río Cauca (Pichindé, Felidia), y conforman el río Cali (Meléndez, Pance, Jamundí, Claro y Timba). Esta riqueza hidrográfica, además de proveer agua a los principales centros poblados y acueductos veredales de los municipios de Cali, Jamundí y Dagua, permite alimentar dos represas (embalses del Alto y Bajo Anchicayá) para generación de energía eléctrica en interconexión con líneas nacionales e internacionales de distribución en el país. ${ }^{1}$

La cuenca hidrográfica del río Jamundí, incluye municipios como Cali y Jamundí, sus principales tributarios son, en orden de importancia, los ríos: Pance, Jordán y Chontaduro, y sus dos sub-cuencas son Río Pance y Río Jamundí. En cuanto a las autoridades ambientales de la cuenca, en el Plan de Ordenamiento y Manejo de la Cuenca Hidrográfica de Jamundí (POMCH) se define que en la zona alta es Parques Nacionales Naturales; en la zona urbana es el Departamento Administrativo de Gestión del Medio Ambiente; y en el resto, es la Corporación Autónoma Regional del Valle del Cauca (CVC). El fundamento conceptual del POMCH 2010 para el ordenamiento de la cuenca es el esquema integral y sistémico de interdependencia de todos los componentes del ecosistema.

El corregimiento de Pance está ubicado en el sur oeste de la ciudad de Cali, y se extiende desde el valle geográfico del río Cauca hasta el Parque Nacional Natural Farallones, límite con el municipio de Buenaventura. Se encuentra dividido en seis veredas: Pance Cabecera, San Francisco, La Vorágine, El Peón, El Banqueo - Pico de Águila. Su población es de 2.359 habitantes y es el corregimiento más grande de Cali, con una extensión de 10.508 hectáreas.

El manejo, planeación y administración de la subcuenca del río Pance, implican el establecimiento de unos marcos normativos que delimitan los parámetros de control y las responsabilidades compartidas o no entre los diferentes actores públicos, privados y de organización de la sociedad civil que actúan sobre el territorio. Actualmente, a la subcuenca del río Pance la cobijan distintos planes, estrategias, programas y políticas ambientales que se han institucionalizado a partir del ejercicio de gobernabilidad de instituciones como el Departamento Administrativo de Gestión del Medio Ambiente (zona urbana), la Corporación Autónoma Regional del Valle del Cauca-CVC (zona 
media) y Parques Nacionales Naturales (autoridad ambiental de la zona alta). Así, el marco normativo regional y local que define los lineamientos estratégicos de administración, control y manejo del territorio que comprende la subcuenca del río Pance son (ver cuadro 1).

CUADRO 1 Marco normativo regional y local de la subcuenca del río Pance

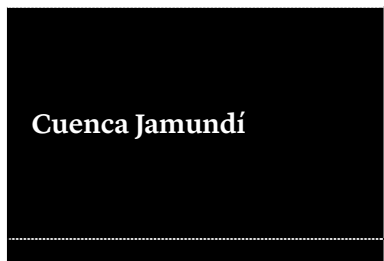

Política Nacional de Gestión de Recurso Hídrico

Plan de Ordenamiento y Manejo de la Cuenca Hidrográfica de Jamundí (POMCH) 2010

Politica Nacional de Gestión de la Biodiversidad y sus servicios Ecosistémicos

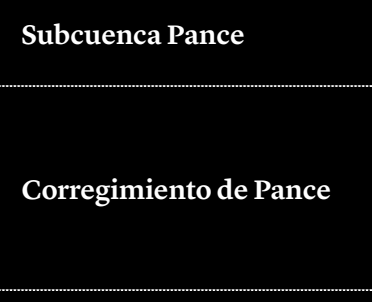

Parque Nacional Natural Farallones
Solamente existe el Plan de Ordenamiento y Manejo de la Cuenca Hidrográfica de Jamundí (POMCH) 2010

Plan Acción Ambiental de CVC 2016

Plan de Ordenamiento Territorial de Cali 2014

Plan de Desarrollo Municipal de Cali 2016

Plan de Desarrollo del corregimiento 2012-2015

Plan de Manejo del Parque Nacional Natural Farallones de Cali 2009

Plan de acción ambiental de PNN 2016

Fuente: elaboración propia.

Históricamente, desde la voz de la memoria de sus propios pobladores, en la primera mitad el siglo pasado, en Pance los primeros baldíos fueron poblados por familias provenientes mayoritariamente del Norte del Cauca, y las actividades económicas giraban en torno a los cultivos de pan coger, la extracción de carbón, y la tala de árboles, generada por el proceso de industrialización del departamento y el desarrollo de medios de transporte como el ferrocarril.

\section{De despensa agrícola y forestal a economía turística}

La creación del Parque Nacional Natural Farallones de Cali, en 1968, y el proceso de declaración de Pance como zona de amortiguamiento del parque, dan una connotación especial a la zona y producen una transformación abrupta de sus prácticas económicas; a tal punto que las restricciones de actividades contrarias a la conservación natural, generaron nuevas formas de apropiación del territorio. Cambió el uso del suelo, la 
caracterización demográfica de la población se modificó a raíz de emigraciones e inmigraciones, y esto conllevó rupturas en los mecanismos de transmisión de saberes del campo, la lógica de cohesión del tejido social asociado a una identidad territorial autoreconocida como campesinado, y se fue acercando a sistemas de valores delineados por prácticas más cercanas a la noción de «vida urbana».

Pance se fue territorializando linealmente, desde las políticas municipales, como una zona con vocación turística. Esto ubica a su población flotante, habitante y migrante dentro de un espacio rural de difusa definición, en tanto pertenece a un proceso de transición de las prácticas y relaciones socioeconómicas, políticas y culturales.

Teniendo en cuenta que territorialización se entiende como el proceso de delimitación de un territorio:

La territorialización sugiere un control determinado por una persona, grupo social o étnico, por un Estado o bloque de Estados. Podemos definir dos tipos de territorialización, una de tipo lineal y otra de tipo zonal. El primer tipo es el que se utiliza para marcar la soberanía espacial y depende de una autoridad centralizada que marca los límites y márgenes hacia el exterior, especialmente en el ámbito de los Estados. La territorialización de tipo zonal está referida a la demarcación que se establece en diversos ámbitos de la vida social y depende de fuerzas orientadas hacia el marcaje de espacios interiores como sucede con distintos grupos sociales en las ciudades o también dentro de las instituciones. (Nates Cruz, 2011: 213).

Es importante anotar que la historia de apropiación de la micro-cuenca, desde las poblaciones humanas que hasta hoy han convivido con los ecosistemas asociados a la cuenca, ha construido diferentes y cambiantes referentes identitarios directamente relacionados con el río y el agua como columna de sus propias formas de organización social. Definiendo apropiación como el proceso por el cual los miembros de toda sociedad se apropian y transforman los ecosistemas para satisfacer sus necesidades y deseos.

Durante la década de los 8o, la expansión de la flotante población turista provoca la emergencia de una oferta de servicios turísticos con mayor diversificación. Se crean restaurantes, balnearios y hoteles, y los habitantes se organizan como guías turísticos. La economía del turismo representa para esta época uno de las economías más prósperas y de mayor proyección de la zona. A principios de la década del 9o, muchos proyectos comunitarios fracasaron por la negligencia estatal, la corrupción en las juntas de acción comunal y la descomposición social del campesinado:

1. Un proyecto de reciclaje comunitario de basuras con un importante componente de educación ambiental.

2. La creación de casas-hoteles, que pretendía adecuar, con la ayuda de la Corporación de Turismo, las casas de varios habitantes como hostales para alojar a los turistas. 
3. La creación de un «retén turístico», con el objetivo de recaudar dineros para invertir en obras que mejoraran la atención a los visitantes.

4. Un sistema de tratamiento de aguas residuales y excretas para que no contaminaran el río Pance.

A medida que fracasaban estos proyectos, aumentaba el desempleo y la desesperación por la situación económica. Algunos relatos de los habitantes consideran que muchos de los jóvenes que no lograron emplearse en la ciudad, se fueron dedicando a la delincuencia; lo que produjo un cambio en las medidas de seguridad: de cinco policías que había en 1981, se aumentó a treinta en 1990. Así, un nuevo actor local interfiere en las dinámicas propias del territorio: grupos armados del frente 30 de las Fuerzas Armadas Revolucionarias de Colombia-Farc. En octubre de 1991, un ataque de la guerrilla a la estación de la Policía de la Vorágine marcó el inicio del control territorial que ejercieron las Farc en la parte alta de la subcuenca durante diez años. Entre 1999 y 2001, algunos líderes guerrilleros desertaron, otros fueron detenidos y otros asesinados, dando fin al periodo de control territorial de las FARC. Después de la caída de estas estructuras, la población de la zona alta vive un periodo de crisis y transformación de sus prácticas de organización comunitaria. Volver a recuperar la confianza entre los vecinos, volver a restaurar las relaciones socio-institucionales, cambiar la mirada sobre la idea de autoridad y autonomía, introduce fácilmente a la población en un proceso de reinvención de la vida comunitaria.

De este proceso emergen formas de organización comunitaria como el Consejo Rural Ambiental de Pance, entre 1999 y 200o; el Comité Agroecológico, que lideró el proyecto «Pance: Pueblo turístico por excelencia»; Cortupance desde 2004, y la Asociación Casa de la Cultura Ambiental de Pance-ACCAP, entre otros.

Mientras la ideología de crecimiento económico a toda costa, característica del sistema económico capitalista, hace de esta micro-cuenca y del agua en cualquier expresión, un recurso de explotación infinito, las primeras formas de apropiación del espacio de esta zona dan cuenta de procesos de construcción de su espacio como territorio rural; entendido como construcción sociocultural del espacio rural ${ }^{2}$ a través de la configuración de relaciones de poder dadas a partir de procesos de apropiación, identificación, experiencia y representación de carácter económico, político y simbólico.

Durante los últimos treinta años el modelo político-económico neoliberal que se incorporó en los procesos de planificación territorial del Valle del Cauca, ha hecho de esta región una de las de mayor proyección industrial, lo que se traduce hoy en

2. Comprendido como cualquier lugar físico geográfico con características naturales que el ser humano concibe como potenciales para su apropiación material y cultural. 
una forma de apropiación económica agresiva de suelos dedicados en su mayoría a la producción de monocultivos de caña que, por un lado, imponen una desarticulación y desorganización de los ecosistemas naturales y, por otro lado, han aumentado la presión demográfica expresada en procesos de urbanización, tecnificación y homogenización de las relaciones económicas. Además de la presión demográfica norte-sur, desde el sur de la cuenca la migración ha sido constante como resultado de la colonización industrial hacia el sur del Valle y el norte del Cauca, lo cual ha intensificado los conflictos territoriales de resistencia que la comunidades rurales de estas zonas (indígenas, campesinos y afrodescendientes) han enfrentado dentro de una historia de conflictos que van de la mano de los procesos de desplazamiento forzado, producto del histórico conflicto armado colombiano, y por la creación de dinámicas económicas ligadas al narcotráfico.

Así, Cali se enfrenta a una planeación deficiente de su expansión urbana, sin ningún tipo de proyección sobre los impactos sociales, económicos y ambientales sobre las diferentes cuencas hídricas del departamento. Son varios los procesos económicos, culturales y políticos que amenazan la sostenibilidad socioambiental de la subcuenca del río Pance, ya que la conservación de la biodiversidad y el manejo adecuado y regulado del agua se ven afectados por la privatización del uso del «recurso hídrico» que hacen las urbanizaciones; por la desarticulación administrativa pública y privada de las autoridades ambientales (DAGMA, PNN y CVC); por la invisibilización de los espacios que cruzan dinámicas rurales y urbanas, la expansión de las principales ciudades de los municipios de Cali (hacia el sur) y Jamundí (hacia el norte) que presionan a Pance; porque no se prioriza la educación integral como estrategia de concientización; por estrategias de conservación ambiental sin oportunidades laborales, el uso de suelos con responsabilidades traslapadas, la activación económica del turismo sin claras competencias de inclusión de la comunidad habitante, la privatización del recurso hídrico en la cuenca baja, la concepción del agua como mercancía ofertada y demandada; por la desarticulación de las organizaciones sociales, la distribución desorganizada de la tierra, la verticalidad de las relaciones de territorialidad, las movilidades demográficas constantes, y por el contradictorio fortalecimiento de un «desarrollo rural» concebido desde el plan de desarrollo nacional, frente al desarrollo industrial de un departamento como el Valle del Cauca.

Todo esto hace de la cuenca, del corregimiento y de la población, un escenario de claras contradicciones sistémicas en lo cultural, político y económico, donde distintas lógicas de relación ser humano-naturaleza, producto de miles de migraciones y configuraciones de identidades dislocadas, resisten a esa dominante estructura de crecimiento y desarrollo económico basado en la sostenibilidad de la productividad. Frente a esto, la probable pero lenta apuesta que la misma comunidad busca, será la de una propuesta de educación ambiental que rompa con las relaciones de oferta-demanda para comprender al ser humano y la naturaleza; y la aprehensión del mismo como sujeto político 
con pensamiento crítico que cuestione las actuales concepciones de «participación», «democracia», e «inclusión».

El entorno capitalista agobia la economía campesina y la empuja a su desarticulación como recurso para garantizar la reproducción de la familia. Junto con ello, el campesino es desplazado de su condición en la escala social. La razón última de esta tendencia a la descomposición no se encuentra en una supuesta explotación del campesino, por el entorno capitalista, ni siquiera en la explicación de cuál es el objeto por el capital comercial sino en su impotencia para seguir el ritmo de los cambios en la productividad. Sin embargo, el capitalismo subdesarrollado destruye la economía campesina y la reconstruye mediante la desarticulación de la empresa capitalista más débil y la expansión de una sobrepoblación cuyas demandas busca satisfacer a través de la distribución de tierras en pequeñas parcelas. (Figueroa, 2005: 49).

Reconstrucción que en la actualidad se hace explícita en Pance, a partir de la configuración y apropiación territorial dada desde las dinámicas de la economía del turismo, donde se oferta y demanda al río como servicio de consumo. Resultan economías basadas en el uso de la tierra para producción de servicios que debilitan las economías de producción agrícola que garantizan la seguridad alimentaria de la población.

\section{Actores rurales de Pance - actores de la ruralidad en Pance}

Intentar definir la «ruralidad» del corregimiento de Pance, significa comprender y analizar el contexto sociocultural del mismo, descrito anteriormente. Como ser vivo, todo ser humano naturaliza su relaciones bioculturales (biológicas, psicológicas y sociales) con el entorno, configurando espacialidades y territorialidades que lo hacen directa o indirectamente un actor (individual-colectivo) con capacidad de agencia sobre las definiciones políticas y económicas claramente determinadas por las lógicas de los sistemas del mismo carácter que las contextualizan históricamente. Una de estas categorías de definición y unidades de caracterización es la «ruralidad», que como construcción social responde a diferentes condiciones políticas, socioculturales y económicas, dependiendo del contexto histórico al que pertenezca. Por su complejidad, esto le da un carácter relacional, cambiante, procesual e histórico a un concepto por lo general definido por oposición a lo «urbano».

En el discurso de la sociología rural, el concepto de ruralidad ha estado frecuentemente asociado a tres fenómenos interrelacionados: una baja densidad demográfica, el predominio de la agricultura en la estructura productiva de una localidad o región, y unos rasgos culturales (valores, creencias y conductas) diferentes a los que caracterizan a la población 
de las grandes ciudades. No existe, sin embargo, un completo consenso entre los académicos. A lo largo del tiempo, diferentes autores han enfatizado uno u otro aspecto, o incluido en su definición varios de ellos. (...) El problema se complica si, además de comparar las definiciones operacionales de la ruralidad, incluimos en el análisis las diferentes imágenes de la ruralidad predominantes en cada sociedad. Hasta fechas recientes, en el imaginario colectivo, el paisaje rural en un extremo solía ser concebido como campos cultivados; y, en el otro, como ecosistemas deshabitados, por lo tanto, sin intervención de los seres humanos. (Pérez y Llambí, 2007: 5-6).

En el caso particular de Pance, la lectura que se puede hacer de la ruralidad como categoría analítica, respondería a tres componentes complementarios:

- Ordenamiento territorial (dimensión político-económica): en Pance la ruralidad es definida a partir del ordenamiento territorial de carácter político- administrativo, donde los corregimientos de la ciudad de Cali corresponden a la zona rural de la misma, en oposición a la zona urbana que comprende las 22 comunas en que está dividida la ciudad. La gobernabilidad de los corregimientos y la toma de decisiones sobre los proyectos, programas y sus presupuestos quedan en gran medida supeditados a las determinaciones del POT.

- Identidad colectiva (dimensión político-cultural): históricamente todos los actores rurales de Pance han construido relaciones de convivencia y conflicto con su entorno y las dinámicas de la globalización y el sincretismo cultural; lo cual ha conllevado a procesos de significación identitaria como estrategias de apropiación de posiciones políticas y de defensa territorial que se construyen a través de subjetividades y colectividades con características tanto de la ruralidad como de la urbanidad.

- Paisaje físico-cultural (dimensión económica-cultural): las transformaciones del paisaje, producto de la interacción ser humano-naturaleza, explicitan las relaciones de lucha de poderes económicos entre los distintos actores sociales, dibujando en el corregimiento distintas territorialidades que intersectan procesos de conservación ambiental, acumulación de riqueza, supervivencia, y urbanización.

Estos componentes interactúan transversal y continuamente a través de sistemas y procesos político-económicos de orden local, regional, nacional y global, como las relaciones de producción capitalista, el neoliberalismo, la democracia y la globalización, traslapados por discursos como el multiculturalismo, las múltiples identidades, la deslocalización, el calentamiento global, el desarrollo, la gobernabilidad-gobernanza, las tecnologías de información, el progreso y la seguridad alimentaria, entre otros.

Esto conlleva claramente a una multisectorialización y polisignificación de los espacios rurales. De acuerdo con Méndez (2012), que existen cambios en la composición poblacional de las localidades asumidas rurales, como resultado de la incorporación de 
actores con intereses diversos, no únicamente agrícolas, orientados por formas distintas de concebir lo rural; lo cual genera la existencia simultánea de múltiples ruralidades.

Sobre esta dinámica de ruralidad se constituyen diversas relaciones entre los distintos actores, sean directas (actores rurales) o indirectas (actores de la ruralidad), teniendo en cuenta la incidencia de estos en la construcción de los distintos espacios y territorios rurales. El primero entendido como cualquier lugar físico geográfico con características naturales de relación e interacción que el ser humano concibe como potenciales para la solución de sus necesidades físicas y equilibrio de sus relaciones culturales. La segunda como la construcción sociocultural del espacio rural a través de la configuración de relaciones de poder por procesos de pertenencia, apropiación, identificación, experiencia y representación de carácter económico, político y simbólico.

CUADRO 2 Relación componentes-dimensiones

\section{POLÍtTICO ECONÓMICO}

Ordenamiento territorial

\section{Ruralidad}

\section{CULTURAL ECONÓMICO}

Paisaje

físico-cultural

\section{POLítico CUltural}

Iidentidad

colectiva

Los actores identificables en Pance son definidos por los tres componentes: ordenamiento territorial (dimensión político-económica), identidad colectiva (dimensión político-cultural) y paisaje físico-cultural (dimensión económica-cultural). Se trata de: Población habitante, Población flotante, Instituciones sociales, Instituciones gubernamentales (sector público), Organizaciones no gubernamentales, Academia, Empresas, Organizaciones Sociales, Comercio, Grupos Armados. Las principales actividades económicas identificables en Pance (ordenadas de mayor a menor cantidad de habitantes que la desempeñan) son: agricultura, ganadería, comercio, construcción, transporte, 
artesanías, gastronomía, alojamiento, guianza, minería, docencia, peluquería, ventas, otros. (POMCH Jamundí, 2010: 14-15).

\section{Ordenamiento territorial y desarrollo}

Como ya se había mencionado, las autoridades ambientales de la cuenca son: Parques Nacionales Naturales en la zona alta, el Departamento Administrativo de Gestión del Medio Ambiente en la zona urbana y la Corporación Autónoma Regional del Valle del Cauca-CVC en el resto. El manejo, planeación y administración de la subcuenca del río Pance implican el establecimiento de unos marcos normativos que delimitan los parámetros de control y las responsabilidades compartidas o no entre los diferentes actores públicos, privados y de organización de sociedad civil que actúan sobre el territorio. Actualmente a la subcuenca del río Pance está cobijada por distintos planes, estrategias, programas y políticas ambientales institucionalizadas a partir del ejercicio de gobernabilidad de instituciones como el Departamento Administrativo de Gestión del Medio Ambiente (zona urbana), Corporación Autónoma Regional del Valle del Cauca-CVC (zona media) y Parques Nacionales Naturales (autoridad ambiental de la zona alta). Así, el marco normativo regional y local que define los lineamientos estratégicos de administración, control y manejo del territorio que comprende la subcuenca del río Pance son: Plan de Ordenamiento y Manejo de la Cuenca Hidrográfica de Jamundí (POMCH), el Plan Acción Ambiental de CVC, el Plan de Manejo del Parque Nacional Natural Farallones de Cali, el Plan de Ordenamiento Territorial de Cali, y el Plan de Desarrollo Municipal de Cali.

\section{Plan de Ordenamiento Territorial-POT de Cali}

Las autoridades ambientales tienen la responsabilidad de velar por el cumplimiento de las normas ambientales, formular herramientas de acción ambiental que promuevan el uso sostenible del medio ambiente, potenciar los procesos de educación y sensibilización ambiental, y contribuir con la investigación de orden socio ambiental, y demás acciones que fortalezcan los procesos de mitigación de los impactos ambientales generados por los conflictos socio ambientales. En el caso del río Pance, los instrumentos de manejo y control ambiental deben ser coherentes con los planes de ordenamiento territorial.

El recién aprobado Acuerdo de Plan de Ordenamiento Territorial de Cali para los próximos 14 años considera al territorio dentro del marco conceptual del desarrollo como un factor básico de crecimiento económico, donde la dimensión urbana ha adquirido un papel importante del desarrollo económico, y considera la integralidad, la intersectorialidad, y la articulación de políticas públicas. 
El modelo identifica a Cali como núcleo central de la región, desde un modelo policéntrico que soporta su complementariedad funcional a nivel regional en la prestación de bienes y servicios; y la planificación dada desde las unidades de planificación rural y urbana. Sus cinco objetivos son:

1. Consolidar una estructura urbana que facilita el desarrollo de la ciudad: integración con la región, complementariedad y especialización económica, cualificación de los entornos urbanos, y mejoramiento de la funcionalidad.

2. Asegurar la sostenibilidad de la ciudad: gestión del riesgo, sostenibilidad ambiental y conservación ecológica, y calidad ambiental.

3. Reconocer y adecuar las dinámicas urbanas hacia los fines de ordenamiento acordados: ciudad densa y compacta, distribución de actividades y definición de tratamientos acorde con las dinámicas urbanas y los objetivos de ordenamiento.

4. Suministrar en forma adecuada bienes urbanos: vivienda, equipamientos, espacios públicos.

5. Hacer del POT un instrumento útil para la construcción colectiva de la ciudad, impulsar proyectos estratégicos, facilitar el desarrollo de proyectos privados, establecer el aporte por edificabilidad, facilitar la comprensión del POT por los ciudadanos.

\section{Teorías del desarrollo y principales enfoques del desarrollo rural}

Los planes de ordenamiento territorial como el de Cali, corresponden a modelos y enfoques de desarrollo que a su vez han sido delineados por las teorías del desarrollo que se describen a continuación. Las cuatro grandes teorías del desarrollo son, según Reyes (2002): la teoría de la modernización, la de la dependencia, la de los sistemas mundiales y la de la globalización.

Los principales supuestos de la teoría de la modernización se basa fundamentalmente en concebir la modernización como un proceso que se realiza a través de fases. De conformidad con la teoría del desarrollo económico de Rostow, para una sociedad en particular existen cinco etapas. Resumiendo, estas son las cinco etapas: (i) la sociedad tradicional, (ii) precondición para el despegue, (iii) el proceso de despegue, (iv) el camino hacia la madurez, y (v) una sociedad de alto consumo masivo. (Reyes, 2002:5).

De acuerdo con la escuela de la dependencia, una de las principales hipótesis referentes al desarrollo en los países del Tercer Mundo: «el desarrollo de los países del 
Tercer Mundo necesita tener un grado de subordinación al centro en contraste del desarrollo de las naciones centrales cuyo desarrollo fue históricamente y es hoy día independiente» (Reyes, 2002: 8).

En cuanto a los principales supuestos de la teoría de los sistemas mundiales, se establece que:

a) hay un fuerte nexo entre las ciencias sociales, especialmente entre la sociología y las disciplinas económicas y políticas. Esta escuela reconoce que generalmente se le da una mayor atención al desarrollo individual de cada una de estas disciplinas que a la interacción entre ellas, y cómo éstas interacciones afectan en términos reales las condiciones nacionales de una sociedad dada; b) en vez de dirigir el análisis a cada una de las variables, es necesario estudiar la realidad de los sistemas sociales; c) es necesario reconocer el nuevo carácter del sistema capitalista. (Reyes, 2002: 12).

Sin embargo, una de las características fundamentales de la teoría de la globalización es que se centra y enfatiza aspectos culturales y económicos así como de comunicación a escala mundial. Esta escuela argumenta que los principales elementos modernos para interpretar los procesos de desarrollo son los vínculos culturales entre los países, además de los vínculos económicos, financieros y políticos. (Reyes, 2002: 15).

Ahora bien, teniendo en cuenta que el nuevo POT está definido desde un enfoque de desarrollo territorial, es necesario reconocer las definiciones sobre el desarrollo rural.

Originalmente en la literatura sobre Desarrollo Rural se pueden identificar dos grandes tendencias interpretativas, la primera de carácter económico, centrada en aspectos productivos, e influida por las nociones de crecimiento y progreso, en tanto la inserción de la producción agrícola de países periféricos a los contextos del mercado de los países centrales, los cuales han basado su desarrollo en el avance urbano - industrial. De otra parte existen los enfoques que se han dedicado a comprender este proceso, privilegiando los aspectos históricos, sociales y políticos, dentro de lo cual se han caracterizado disciplinas científicas como la sociología rural y la antropología especialmente. Dichas miradas han contrapuesto y diferenciado en sus concepciones, lo rural de lo agrario, generando una falsa dicotomía, que en la práctica, no se revelan como diferenciales sino como dinámicas complementarias. (Pérez, 2012: 3).

En esta medida y de acuerdo con Machado (2002) se pueden identificar los siguientes enfoques:

- El Enfoque Estructuralista.

- $\quad$ El Enfoque del Marxismo - renovado. 
- El Enfoque Neo-Estructural.

- El Enfoque Neoliberal.

- El Enfoque Neo-Institucional.

En cuanto los nuevos enfoques de gestión del desarrollo rural:

En las últimas cuatro décadas de siglo XX, la disposición del territorio en América latina y particularmente para el caso colombiano, se ha definido por diversas tendencias económicas y políticas, a partir de las cuales, según lo plantea Moncayo (2004), se nutre un modelo de desarrollo tendiente a «(...) la competitividad, el ordenamiento territorial a escala urbana y nacional, una dependencia a la reestructuración económica internacional, la sostenibilidad de los recursos naturales; y la configuración de ciudades empresariales bajo el compromiso de las economías locales. (Pérez, 2012: 9).

Desde esta perspectiva se construye el enfoque territorial identificado en el POT como una tendencia que según Pérez (2012), «se ha venido materializando en las políticas públicas y la planeación del desarrollo del medio rural como respuesta a las actuales directrices del desarrollo. Desde donde se mantiene el privilegio de un modelo de competitividad económica global sobre los atributos sociales, recursos naturales y formas de producción local alternativa».

¿Cómo se manifiestan los efectos de aplicación de estos modelos y enfoques en este territorio?: Como se ha descrito, el modelo económico imperante e imponente no solo ha permeado los espacios y territorios rurales, sino que ha impedido y transgredido los sistemas de valores de sociedades que fueron obligadas a cambiar sus economías. El sistema económico permeó todas las otras esferas de la vida biológica y pasó a traducir todas las relaciones y prácticas humanas al lenguaje de la valorización de todas las acciones. Se ha mercantilizado y valorizado el mundo social y biológico desde una perspectiva no de uso, sino de valor de cambio.

En el corregimiento de Pance, los conflictos por las formas de uso del suelo, de ocupación del territorio y de definición de las territorialidades, son la expresión de los conflictos ecológicos. Actualmente, Pance es un territorio donde confluye una gran diversidad de tensiones entre actores involucrados en el uso, acceso, explotación y conservación de elementos naturales como el agua y la tierra, aunque estos no están relacionados directamente con la población flotante. Existen otras tensiones recurrentes manifestadas por la población que se producen particularmente en cada vereda. Son las siguientes: 


\section{Veredas Pance Cabecera}

Más de 40 viviendas de la zona alta del corregimiento que colinda con Parques Nacionales Naturales se encuentran en un pleito jurídico con PNN - Farallones de Cali sobre la legalidad de sus propiedades (predios, lotes, viviendas, etc.), ubicadas según resolución 0092 de 1968 dentro de la zona de protección del parque. Proceso que ha puesto en riesgo de reubicación a varias familias de la zona, generando diversos procesos de resistencia y defensa de sus territorios, en contra de la ordenanza de PNN.

\section{Vereda San Francisco}

Un polígono de esta vereda fue declarado en el último POT de Cali (2014) como zona de riesgo no mitigable por deslizamiento de tierra, lo que ha producido negativas por parte de la Alcaldía de Cali para la inversión pública en saneamiento básico. Como consecuencia, la población afectada por la cancelación de los proyectos de inversión pública y por la posible orden de desalojo de las viviendas en zona de riesgo, adelanta procesos de organización interna para apelar a la Alcaldía con recursos jurídicos para que se les reconozca el derecho a una segunda evaluación de la zona, en búsqueda de defender sus propiedades y tierras.

\section{Vereda la Vorágine}

Desde 1992, Emcali -Empresas Municipales de Cali- venía identificando el río Pance como una alternativa de abastecimiento de agua para la ciudad. Se contrató a la empresa Ingesam para la realización del estudio de factibilidad de un acueducto de Pance que diera solución al área de influencia en cotas entre 1.030 y 1.200 msnm. En 2005 la comunidad en desacuerdo con el proyecto instauró una acción popular sobre Emcali EICE-ESP, la Alcaldía Municipal y la Corporación Autónoma Regional (CVC) por el impacto ambiental de un proyecto de estas magnitudes. El proceso de implementación del proyecto se detuvo posteriormente por los efectos de la acción popular. Un estudio de impacto realizado por el Instituto Cinara de la Universidad del Valle, contratado como perito para conceptuar si el proyecto vulneraba los derechos colectivos de la comunidad, cuyos resultados se conocieron en 2014, reconoce la baja viabilidad económica, social, jurídica, ambiental y técnica del proyecto. Sin embargo la comunidad aún no confía en que esto haya sido suficiente.

En 2014 la Parcelación Chorro de Plata y algunos líderes comunitarios iniciaron un proceso de investigación sobre las irregularidades presentadas por la empresa de servicios turísticos La Cascada de Pance, que aprovechó ilegalmente el agua al construir una piscina en el lecho y ribera del rio Pance, tiendas en la zona forestal protectora aguas abajo del río, una batería de baños que vierten las aguas servidas sin tratamiento alguno 
y sin permiso de vertimiento, un puente y una cerca contigua a la ribera aguas arriba. Además taló un número indeterminado de cascarillo, mortiño, yarumo y otros árboles nativos en la zona forestal protectora del río con el objeto de construir una vía de acceso a una cascada ubicada en un área de importancia estratégica para la conservación del recurso hídrico del cual se surten los acueductos de la Vorágine y de la Parcelación Chorro de Plata. Actualmente está vigente el proceso jurídico contra la empresa, ya que a pesar de la medida preventiva que impuso CVC para la suspensión inmediata de las actividades de turismo, recreación y hotelería realizadas en ese establecimiento de comercio, a los quince días se levantaron las cintas y sellos de cierre puestos por la CVC.

En 2014 se llevó a cabo una movilización social de los habitantes y usuarios del Río Pance contra la concesión administrativa del Ecoparque a una entidad privada (Fundación Pachamama), que se realizó sin previa consulta o concertación con la comunidad y violando el debido proceso de convocatoria pública. Frente a esta situación, la comunidad se organizó a través de una Mesa de Defensa del Ecoparque e interpuso un derecho de petición y un proceso de control político ante la Asamblea Departamental, además de una marcha de denuncia, y un foro público para defender el Ecoparque como patrimonio natural y cultural, y los derechos al acceso público del agua y el derecho a la concertación.

Aunque se logró la cancelación del contrato a Pachamama, no se ha logrado el cumplimiento a cabalidad de los acuerdos pactados entre la Gobernación Departamental y la comunidad. Sin embargo, el proceso refleja la capacidad de control de los habitantes sobre su territorio en la búsqueda de espacios de reconocimiento y legitimidad del derecho a la participación en la planificación territorial.

\section{Vereda El Banqueo}

Esta vereda está ubica al suroriente del corregimiento y su manejo político administrativo está integrado al de la Junta de Acción Comunal de Pico de Águila, a pesar de considerarse una vereda diferente. Es una de las veredas con menor capacidad de drenaje hídrico y el aumento de su densidad poblacional ha conllevado a que la JAC incorpore medidas de regulación del uso del agua, como los contadores, pero la administración del cobro de los mismos no ha dado confiabilidad a sus usuarios, puesto que los cobros en las facturas sobrepasan la capacidad de pago de los habitantes. En respuesta a lo anterior y con el ánimo de resolver la poca legitimidad de los líderes de esta JAC entre los habitantes de Banqueo, la vereda está en un proceso de conformación de una nueva JAC ante el comité de planificación del corregimiento. Los mismos habitantes han dispuesto mecanismos de organización comunitaria para hacer oposición a un proceso que no acompañe el control por la vía del cobro económico, actividades de educación ambiental sobre los usos del agua y procesos de veeduría ambiental sobre los nuevos asentamientos que sobrecarguen la capacidad de abastecimiento de agua de la zona. 
Los procesos de organización y asociatividad percibidos en la historia de los habitantes de la microcuenca, dan luces sobre los lugares y espacios de resistencia y oposición frente al modelo de crecimiento económico. Desde la comunidad, uno de los espacios de interlocución más importantes para los actores sociales asociados a la planeación del territorio que comprende la sub cuenca del río Pance, es la Mesa Ambiental. Definida como un espacio abierto de concertación por el derecho a un ambiente sano a la vida y al territorio entre organizaciones comunitarias, sociales, y entidades públicas; para potenciar o desarrollar soluciones a las situaciones ambientales de la subcuenca del Rio Pance y las microcuencas del corregimiento.

Además de la Mesa Ambiental, hay otros colectivos locales, asociaciones u organizaciones que desarrollan proyectos educativos o actividades ambientales que promueven la cohesión social a pesar del escaso apoyo y reconocimiento que reciben de las estructuras formales de organización comunitaria y participación ciudadana. Algunas de éstas son:

\section{Colectivo Ukumari}

Desde el refugio agroecológico «Pacho Villa», ubicado en la vereda del Pato Alto, viene desarrollando: 1. letrinas composteras secas; y 2. agricultura a partir de energías sutiles. Estos dos proyectos son vitales para la comunidad, dado que por un lado significan dejar de contaminar el rio con materias fecales, y por otro lado dialogan con la comunidad acerca de la agricultura limpia con semillas nativas, como lo hacían nuestros ancestros y también con algunas técnicas heredadas de la ciencia. Algunos de sus productos alimenticios son tortas integrales de granola, quinua, maní y pan integral.

\section{Asociación Casa de la Cultura Ambiental}

Organización sin ánimo de lucro, ha realizado actividades de investigación, conservación y protección. Entre sus acciones ambientales por Pance están: la recopilación de la memoria histórica de Pance y la construcción colectiva de un documental sobre identidad cultural; la implementación de un modelo innovador, educativo y de sensibilización ambiental; el desarrollo de herramientas pedagógicas para la comprensión del Territorio; la implementación de la campaña Amigos del Rio Pance y de jornadas de limpieza y revitalización del Rio Pance, la comparsa por el agua y el registro de situaciones ambientales en la cuenca baja y media del rio Pance.

\section{Junta de Acción Comunal de Pance cabecera con ARTANS}

Sus objetivos son mitigar el impacto ambiental generado por RS, generar cultura de la no basura, crear tejido social a través del RS, y generar ingresos económicos con el RS. Entre sus acciones están: con la Institución Educativa Pance realizan un diagnóstico de RS para crear alternativas de solución; transformación constante del RS para «Re- 
utilizacion»; charlas con los turistas sobre manejo adecuado del RS; talleres con los generadores de residuos que prestan servicios turísticos; adecuaciones de las unidades de almacenamiento colectivo para el turista; avisos de conciencia; socializaciones e integración con las diferentes veredas del corregimiento.

\section{Colectivo EnamorArte}

En su mayoría son jóvenes de Pance Cabecera que desarrollan acciones como ollas comunitarias, jornada de murales, trueques, mingas de limpieza y recuperación del parque y construcción de huertas. En sus palabras: «Queremos que cada persona participante y cercana al proceso se sienta como en un bonito sueño, en un proceso de sanación y reconciliación consigo mismo y con los demás. Los invitamos a continuar este mágico viaje, por este, en el camino de la recuperación de nuestros espacios comunes, de saberes ancestrales, de interacción y dialogo que nos permita, Enamorarnos del territorio y de esta manera contribuir a desarrollar nuestras capacidades en pro de un bienestar social común».

\section{Peón Pazy Amor}

Colectivo de jóvenes afrodescendientes de la Vereda El Peón (corregimiento de Pance), desde el 2013 se reúnen pensando en transformar sus vidas y ayudar a transformar su comunidad. Analizan críticamente sus vidas y emprenden acciones para que sus realidades cambien, contribuyendo a la organización, unión y desarrollo de la vereda.

\section{Biblioteca Pública Comunitaria}

Desde el 1 de agosto del 2005 hace parte de la Red de Bibliotecas de la Secretaria de Cultura y Turismo de Cali, con este apoyo ha logrado adecuar su espacio físico y aumentar su acervo bibliográfico, además de adquirir la figura de «publica comunitaria»desde la gobernabilidad. Está ubicada en Pance Cabecera, cerca del Parque Natural Farallones, donde los recursos naturales se relacionan con la comunidad en sus actividades diarias, al igual que con los turistas que siempre vienen en busca de ocio. Por esta razón su proyecto transversal gira en torno de la cultura ambiental, al alcance de la comunidad usuaria, vecinos, amigos y visitantes. La biblioteca cuenta con un grupo ambiental, Leo $y$ Rio en el Nilo, integrado por 40 infantes a los que se les imparte promoción y animación a la lectura, conciencia ambiental, amor por el entorno y sentido de pertenencia para que se conviertan en multiplicadores en el territorio como vigías ambientales del patrimonio natural del parque.

En la Vorágine, los habitantes están organizados principalmente en dos asociaciones: la Asociación de Usuarios de Acueducto y Alcantarillado-Asovorágine, y la Asociación de ribereños de Pance. Ambas trabajan por el cuidado ambiental de la vereda. 
Es de resaltar la urgencia con que se buscan estrategias, desde la comunidad, para ampliar la mirada de su territorio hacia una mirada holística e integral que garantice el fortalecimiento de las herramientas de planeación no de un corregimiento, sino una micro-cuenca, como sistema complejo abierto de circulación de flujos de materia y energía en el que conviven distintos ecosistemas. con uno de los elementos más preciados por la humanidad y, en este caso específico, por la ciudad de Cali: el agua. Además de una perspectiva administrativa de la economía de los recursos, acá se propone que esta se a una que incluya miradas socio-antropológicas, desde la física, la filosofía, la ecología económica y política.

Los ecosistemas de la microcuenca de Pance se han ido transformando según han sido «apropiados». Según Toledo (2008) esta «apropiación» es material e intangible y se traduce en un acto de internalización, momento específico de articulación material del ser humano a la naturaleza a través del trabajo. Toledo explica que existen tres formas de apropiación: una sin cambios sustanciales de los ecosistemas, una segunda que desarticula y desorganiza los ecosistemas, y una tercera que no produce ningún tipo de acción. Estas formas de apropiación dan lugar a tres tipos de mega-paisajes del ambiente: el primero es el MAU: medio ambiente utilizado; el segundo es el MAT: medio ambiente transformado; y el tercero es el MAC: medio ambiente conservado.

Si volviéramos a la contextualización histórica y a la caracterización territorial sobre el río Pance, fácilmente podríamos encontrar que la microcuenca, desde su propio devenir histórico cambios en su paisaje; hoy encontramos traslapados los tres tipos de mega paisajes que Toledo identifica como resultado también de los usos sociales que se han generado, sea desde lo rural, lo urbano o lo industrial.

Por tanto, acá se propone comprender que estamos frente un sistema que implica la ambigüedad del límite borroso entre ruralidad y urbanidad. Es decir, sus paisajes han sido absorbidos y transformados por Cali; así como las formas de apropiación del medio ambiente, ya que han adquirido la categoría de áreas de conservación, donde la unidad de Parques Nacionales Naturales ha restringido la vivienda, el cultivo y la extracción de fauna y flora en las zonas de reserva.

En esta medida, la responsabilidad de las formas de organización política comunitaria y de los demás actores de la microcuenca interesados por la planeación del futuro del río Pance y sus ecosistemas asociados, son los que deben decidir, con criterios contundentes y críticos, las formas de apropiación que mejor se acerquen a la garantía del ajuste ecológico.

En respuesta a este panorama, la comunidad no solo se ha organizado alrededor de la mencionada Mesa ambiental, sino también a través de la Mesa por la defensa el ecoparque y del río Pance, en la zona baja de la subcuenca. Durante los últimos 2 años, los espacios de identificación de los conflictos socioambientales promovidos por el Departamento de Planeación de la Alcaldía de Cali, dentro del proceso de diagnóstico para la formulación del POT, se convirtieron en espacios de dialogo y encuentro claves 
para el reconocimiento de la corresponsabilidad de la comunidad frente a la planeación de su territorio.

Durante estos años la comunidad buscó poner en marcha diversas estrategias de organización local, pero solo hasta finales del año 2014, con la suspensión de la entrega de la administración del ecoparque, la coyuntura obligó a algunos sectores de la comunidad a crear la mesa por la defensa del ecoparque del río Pance, cuyo primer objetivo fue exigir a la Gobernación una justificación sobre las razones por las que se entregó la administración a la Fundación Ecológica Ambiental Pacha Mama. El resultado de diversos debates públicos fue el estudio de cuatro posibles nuevos administradores: la misma Gobernación del Valle, el Dagma, la Corporación para la Recreación Popular o Corpocuencas. Al final, el comodato se otorgó a la Corporación para la Recreación Popular. Paralelamente, se fortaleció el comité de planificación que garantizará la representatividad y participación de los diversos actores locales en la toma de decisiones de planeación del territorio.

\section{Consideraciones finales}

$\mathrm{Al}$ aproximarse al caso del corregimiento de Pance de la ciudad Cali (zona de amortiguamiento del Parque Nacional Natural Farallones), claramente se puede deducir que muchos de los conflictos socioambientales asociados a la subcuenca del río Pance, se generan en gran medida por el actual modelo de territorialización que las autoridades de control ambiental han desarrollado sobre esta zona.

Las autoridades han fragmentado la subcuenca en tres territorios, objeto de administraciones de tres escalas distintas que responden a políticas diversas. En el orden nacional, PNN es la competencia de regulación ambiental de la zona alta y sus políticas actualmente se concentran en la recuperación de la franja de protección que impide radicalmente la posibilidad de asentamientos humanos y producción agrícola. En la zona media, CVC se ha concentrado no solo en la implementación de políticas de protección y conservación de esta zona amortiguadora del PNN, impulsando las actividades de turismo ambientalmente responsable y una habitabilidad consecuente con el manejo y uso regulado de las fuentes hídricas. En la zona plana o baja, el DAGMA ha autorizado y adjudicado licencias al proceso desbordado de construcción de viviendas y urbanizaciones que amenazan la sostenibilidad ambiental y que eliminan todo rastro de las actividades agrícolas campesinas, además de la saturación ejercida por la agroproducción de caña sobre la subcuenca en la zona de la desembocadura en el río Jamundí.

$\mathrm{Si}$ se considerara que el modelo de uso de suelo para turismo instaurado en la subcuenca puede ser un claro ejemplo de economía rural no agrícola, preocupa cómo las políticas de planeación territorial (sea POT o el plan de manejo de la cuenca hídrica) 
se convierten en un impedimento o barrera para el pleno desarrollo de las actividades agrícolas. Entendiendo por economía rural no agrícola toda actividad económica que no es producto de la agricultura (manufactura o servicios); esta se caracteriza en diversas zonas del país como un fenómeno de multifuncionalidad y pluriactividad de las economías rurales. Lo cual implica que muchas de las actividades económicas que generan los ingresos locales de las familias rurales están diversificadas. Una misma familia puede vivir de una economía agrícola combinada con una actividad de manufactura o prestación de servicios. En el caso del sector turismo, que es una de las economías con mayor incremento en América Latina, en muchas regiones o localidades se observa cómo la prestación de servicios turísticos se convierte en una de las economías motores de la población rural.

La lectura de las teorías, enfoques y modelos de desarrollo descritos demuestra que el documento de acuerdo del Plan de Ordenamiento Territorial de Cali responde a un enfoque territorial de desarrollo urbano-rural que no reconoce las economías agrícolas de sus habitantes. Ejemplos: los apoyos de la Umata a los campesinos se restringen cada vez más los perfiles de sus beneficiarios; los empresarios de grandes centros recreativos de la Vorágine invisibilizan en sus proyectos productivos la existencia de los campesinos; la planificación de las inversiones públicas en el corregimiento están encaminadas exclusivamente a la infraestructura física o programas sociales dirigidos a promover el turismo de la zona y no a otras economías mixtas que allí se conjugan.

Ahora bien, teniendo en cuenta la historia de configuración territorial de Pance y su actual composición demográfica, lo más pertinente para su desarrollo integral sería la combinación de actividades agrícolas y no agrícolas, sin embargo, la proyección del uso del suelo se enfoca solo a la prestación de servicios turísticos; esto complejiza las prácticas y relaciones socio-económicas de la población habitante del corregimiento. Su calidad de vida se ve afectada, y su cercanía a Cali da lugar a una pluriactividad que se caracteriza por procesos de inclusión de esta población rural a la oferta laboral de la ciudad de Cali (servicio doméstico, construcción, seguridad privada, etc.).

Esta cercanía a Cali la convierte, además, en una zona de conurbación, entendida como una forma de adaptabilidad que evidencia espacios de hibridación, típicos de las periferias de las grandes ciudades del país. Al igual que Bogotá, Cali presenta una alta ruralidad que no es percibida ni por el imaginario social ni por las instancias gubernamentales que invisibilizan desde sus políticas la importancia de las poblaciones de las zonas rurales. Teniendo en cuenta que esos procesos de adaptabilidad son socio-históricos, políticos, económicos y ambientales, vale la pena resaltar que los enfoques de la gestión ambiental territorial de las distintas autoridades competentes deberían corresponder con el reconocimiento de esas trayectorias. Quedan abiertos los cuestionamientos sobre los enfoques de las políticas que entienden dicotómicamente las realidades urbanas y rurales. Si bien nos enfrentamos a nuevas ruralidades donde la condición de hibridación 
es cada vez más clara, la formulación de las políticas y sus enfoques metodológicos deberían también ser coherentes con estos espacios que no son solo urbanos o rurales, sino más cercanos a realidades que expresan relaciones y prácticas mixtas.

Las más recientes transformaciones e impactos de los lineamientos del POT sobre la población rural, son los cambios en sus estructuras organizativas, que durante los últimos cuatro años de diseño del mismo han buscado ejercer el derecho al reconocimiento de su capacidad de participación e incidencia política para demandar estrategias de solución a los conflictos socio-ambientales, como es el caso de la consolidación de la mesa ambiental, la mesa para la defensa del ecoparque o el comité de planificación.

Los actuales procesos de organización y asociatividad que se perciben en la historia de los habitantes de la microcuenca, dan luces sobre los lugares y espacios de resistencia y oposición frente al modelo de crecimiento económico. Desde la comunidad, uno de los espacios de interlocución más importantes para los actores sociales asociados a la planeación del territorio que comprende la subcuenca del río Pance es la Mesa Ambiental, que ha sido definida como un espacio abierto de concertación por el derecho a un ambiente sano a la vida y al territorio entre organizaciones comunitarias, sociales, y entidades públicas para potenciar o desarrollar soluciones a las situaciones ambientales de la subcuenca del Rio Pance y las microcuencas del corregimiento.

Dentro de la agenda de la Mesa Ambiental del Corregimiento de Pance han estado presentes los casos, han apoyado la gestión de trámites o procesos que fortalezcan la defensa del territorio y sus elementos sociales y ambientales. Frente a este escenario, distintos sectores de la comunidad local se han esforzado por construir proyectos de interés ambiental, cuyos modelos han correspondido en algunos casos a enfoques de sostenibilidad y en otros casos más a modelos cercanos a las teorías del desarrollo sustentable, dando respuesta a sus intereses sobre el territorio, ya sean de investigación, educación, recreación, protección, producción agrícola o promoción de servicios turísticos.

Además, la Mesa Ambiental ha promovido la visibilización de cada uno de los procesos ante el comité de planificación, Junta de Acción Local, cabildos abiertos, medios de comunicación y socializaciones de proyectos externos que buscan realizar intervenciones o investigaciones en el territorio. Se ha convertido en un veedor colectivo ciudadano, apoyando el seguimiento de los mismos casos hasta donde les sea permitido con los medios que tienen, y han aportado al proceso de diagnóstico socio ambiental en la identificación de las situaciones ambientales.

En general, la Mesa Ambiental es un espacio aún en proceso de construcción con diversas debilidades en su cohesión social, como resultado de las múltiples divergencias en las posiciones, intereses y compromisos de sus miembros. A pesar de esto, ha logrado un reconocimiento por gran parte de la comunidad y las instituciones, lo que contribuye a consolidar el camino hacia la legitimación de la misma en los espacios de toma de decisiones como las Juntas Administradoras de Agua, las Juntas de Acción Comunal 
y la Junta de Acción Local. El primer paso fue lograr que este año se reconociera a un delegado de la Mesa Ambiental en el Comité de Planificación de Pance, generando visibilidad de sus acciones y propuestas, y relevancia del rol que cumple dentro del territorio.

Las comunidades que se han movilizado se enorgullecen por los logros alcanzados; sin embargo se sienten cansados, manipulados, vulnerados, engañados y amenazados por las grandes maquinarias políticas de las instituciones públicas y privadas. Por generaciones las comunidades han defendido el territorio, se han unido, quebrado y reintegrado en diferentes niveles, pero sobre todo se han decepcionado de la falta de legitimidad que las instituciones les han dado. En Pance las movilizaciones sociales han sido síntoma, consecuencia y solución de los conflictos, se han creado sinergias, redes de apoyo y alianzas para hacer valer los derechos a la divulgación, la denuncia, la expresión y la comunicación de todas las etapas de desarrollo de los conflictos. Se han propiciado los espacios para visibilizar y construir tejidos marcados por las relaciones comunitarias.

En consecuencia, este un claro ejemplo de cómo todas aquellas acciones que las entidades privadas o las organizaciones de la sociedad civil formulen y ejecuten en articulación con las autoridades ambientales del sector público, promoverán la emergencia de procesos de participación que garanticen el buen manejo, la gestión participativa y la recuperación de los sistemas ambientales, lo cual a su vez permite el pleno desarrollo de las actividades que ellos han descrito como el conjunto de acciones necesarias para «vivir bien».

\section{Referencias}

AGUIRRE, S. (coord.). (2001). Espacio y territorios: razón, pasión e imaginarios. Bogotá: Universidad Nacional de Colombia.

ARDILA, G. (2006). «Cultura y Desarrollo Territorial». Ponencia presentada en el Diplomado en Gestión de Procesos Culturales y Construcción de lo Público por el Instituto Distrital de Cultura y Turismo en Bogotá el 29 de julio de 2006. http://www.culturayturismo.gov.co/cultura_y_turismo/ sistema_distrital_de_cultura/diplomado/Ponencia\%20Gerardo\%20Ardila.pdf

BARDACH, E. (1998). Los ocho pasos de para el análisis de Políticas Públicas. Un manual para la práctica. México: CIDE.

CORPORACIÓN AUTÓNOMA REGIONAL DEL VALLE DEL CAUCA - CVC, Subdirección de Planeación Grupo de Planificación Ambiental. [et. al.] (2003). Plan de Gestión Ambiental Regional del Valle del Cauca 2002-2012: «Participación con Compromiso». Isabel Cristina Mosquera López; Rodrigo Humberto Escobar Holguín; Patricia Libreros López, [et. al.], Santiago de Cali: CVC. 
CORPORACIÓN AUTÓNOMA REGIONAL DEL VALLE DEL CAUCA - CVC, Subdirección de Planeación Grupo de Planificación Ambiental. [et. al.] (2010). Plan de Ordenación y Manejo de la Cuenca Hidrográfica del Río Jamundí. Santiago de Cali: CVC.

DEPARTAMENTO ADMINISTRATIVO DE PLANEACIÓN MUNICIPAL DE CALI (2014). Documento técnico de soporte revisión y Ajuste del Plan de Ordenamiento Territorial de Santiago de Cali. Subdirección del POT y Servicios Públicos. Santiago de Cali, Junio de 2014.

DIRECCIÓN GENERAL AMBIENTAL SECTORIAL. (2002). Guía de Gestión Administrativa para la aplicación del SIGAM. Grupo de Gestión Urbana y Salud. Sistemas de Gestión Urbana FIGAU

FIGUEROA, V. M. (2005). «América Latina: descomposición y persistencia de lo campesino». Revista Problemas del Desarrollo, México, 36(142). Disponible en: http://probdes.iiec.unam.mx/interiores/ numero142.htm, 28 de octubre de 2005 .

FUNVIVIR. (2005). Mapa Social del corregimiento de Pance. Proyecto: «Asistencia Cívica, Socialy Técnica en Actividades Agroecoturísticas en la Zona Rural de Santiago de Cali». Cali: Alcaldía Municipal de Cali y Umata.

MARTÍNEZ ALIER, J. (2008). Conflictos ecológicos y justicia ambiental. Papeles (103).

MENDEZ, M. (2012). Lo rural diversificado: ampliación de la existencia rural y existencia simultánea de múltiples ruralidades. Maestría Sociedades Rurales Universidad de Caldas, Manizales.

MINISTERIO DE AMBIENTE, VIVIENDA Y DESARROLLO TERRITORIAL. (2010). Política Nacional para la Gestión Integral del Recurso Hídrico. Bogotá, D.C.: Colombia, Ministerio de Ambiente, Vivienda y Desarrollo Territorial.

NATES CRUZ, B. (2011). Soportes teóricos y etnográficos sobre conceptos de territorio. Revista Co-herencia, 8(14), 209-229.

PÉREZ, E. y Llambi, L. (2007). Nuevas ruralidades y viejos campesinismos. Agenda para una nueva sociología rural latinoamericana. Cuadernos de desarrollo rural, 4(59), 37-61.

PÉREZ, M. y Rojas, J. (2008). Desarrollo Sostenible: Principios, aplicacionesy lineamientos de política para Colombia. Universidad del Valle - Instituto Cinara. Cali, Octubre.

PÉREZ, M (2012). Tendencias interpretativas en la concepción del desarrollo rural. (Documento para Discusión). Grupo Dialogo Rural Colombia.

PÉREZ, S. y Zúñiga. (2014). Conflicto ambientales en el rio Pance entre diversos usos y usuarios del agua. Cali: Instituto Cinara.

PÉREZ-RINCÓN, M.A. (2014). Conflictos ambientales en Colombia: Inventario, caracterización y análisis. Cali: Universidad del Valle/Instituto de Investigación y Desarrollo en Abastecimiento de Agua, 
Saneamiento Ambiental y Conservación del Recurso Hídrico - CINARA/ Environmental Justice Organizations, Liabilities and Trade (EJOLT)

REYES, G. (2002) Principales teorias sobre desarrollo económico y socialy su aplicación en América latina y el Caribe. Disponible en: http://www.zonaeconomica.com/files/teorias-desarrollo.pdf

SISTEMA DE INFORMACIÓN AMBIENTAL DE COLOMBIA-SIAC. (2002). Primera Generación de Indicadores de la Linea Base de la Información Ambiental de Colombia. Tomo 2.

TOBASURA, I. (2006). La Política Ambiental en los Planes de Desarrollo en Colombia 199o-2006. Una Visión Crítica. Revista Luna Azul (22) Universidad de Caldas. Recuperado el día 15 de marzo de 2009. En: http://lunazul.ucaldas.edu.co/downloads/dbdceba9Revista22_2.pdf

TOLEDO, V. M. (2008). Metabolismos rurales: hacia una teoría económico-ecológica de la apropiación de la naturaleza. Centro de Investigaciones en Ecosistemas, Universidad Nacional Autónoma de México, Campus. Morelia, México.

VEGA, L. (2001). Políticas Públicas hacia el Desarrollo Sostenible y Política Ambiental hacia la Sostenibilidad del Desarrollo. Bogotá, D.C. 